\title{
Manejo del dolor en pacientes quemados
}

\author{
BELÉN LARREA A. ${ }^{1}$, MARCELA ÁVILA Á. ${ }^{2}$, CINDY RADDATZ M. ${ }^{2}$
}

\author{
Hospital del Trabajador. \\ Hospital de Urgencia Asistencia Pública, Universidad de Santiago.
}

Key words: Pain management, burns.

\section{Introducción}

La máxima agresión física que puede sufrir un ser humano son las quemaduras, siendo la forma de trauma más grave y doloroso que un paciente puede sufrir ${ }^{1-3}$.

Se estima que en Chile alrededor de 9.000 personas se hospitalizan anualmente por quemaduras, con una tasa de mortalidad que ha disminuido considerablemente en los últimos 20 años ${ }^{4}$.

El aumento en la intensidad del dolor se debe a que las quemaduras lesionan los receptores dérmicos y con esto se produce una amplificación nociceptiva, que llevará a la alteración de la función de percepción, transmisión y modulación del estímulo doloroso ${ }^{5,6}$.

El manejo del dolor es fundamental para evitar la aparición de dolor patológico que llevará a los pacientes a la manifestación de dolor crónico y con ello al desmedro en su calidad de vida ${ }^{7}$.

Desafortunadamente, el subtratamiento del dolor en los pacientes quemados es una reali$\mathrm{dad}^{8-12}$. Una explicación de este fenómeno es la falta de conocimiento de la neurofisiología del dolor, el desconocimiento de su manejo terapéutico y los mitos asociados al uso de opioides.

\section{Neurofisiopatología del dolor por quemaduras}

El entendimiento de los mecanismos básicos de la percepción del dolor ha progresado en los últimos años gracias al avance de las neurociencias. También ha sido de gran interés el estudio de la hiperalgesia y su relación con el dolor ocasionado por las quemaduras ${ }^{13}$.

Es sabido que los numerosos procedimientos para tratar las quemaduras producen estímulos dolorosos intensos, repetitivos y prolongados en el tiempo, dando origen a la alteración patológica de la función de percepción, transmisión y modulación del estímulo nociceptivo, logrando con esto la amplificación de las zonas receptivas y a la alteración de la relación entre la intensidad del estímulo doloroso y la respuesta al dolor (Figura 1).

Las quemaduras producen un aumento de la intensidad dolorosa, debido principalmente a los siguientes mecanismos:

- La intensidad del dolor es proporcional a la superficie corporal quemada; la cantidad de nociceptores dañados aumenta proporcionalmente al aumento de la superficie corporal quemada.

Correspondencia a:

Dra. Marcela Ávila Á.

maravila7@gmail.com 


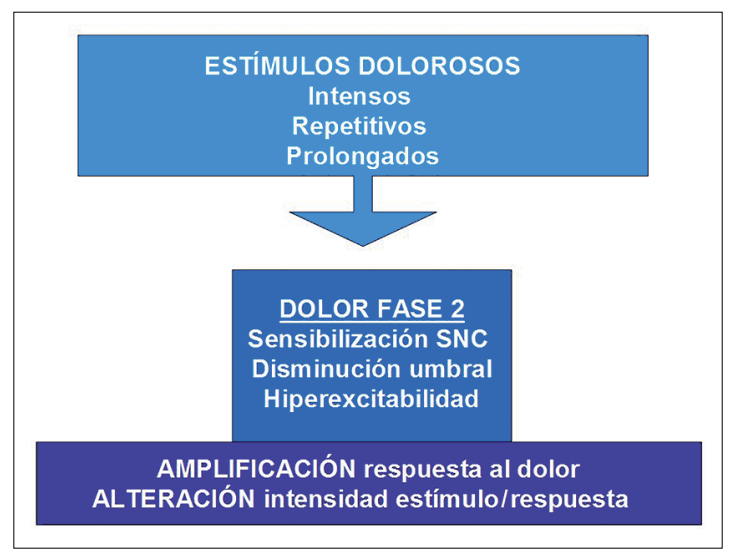

Figura 1. Neurofisiopatología del dolor ocasionado por las quemaduras.

- El daño de la epidermis y dermis por las quemaduras produce lesión de las terminaciones libres nociceptivas, lo que explicaría la hipótesis del componente neuropático desde un comienzo ${ }^{13}$.

- Procedimientos terapéuticos dolorosos, fundamentales para la cicatrización de las heridas.

\section{Mecanismos generadores del dolor por quemaduras}

\section{Componente nociceptivo ${ }^{14-17}$}

El daño tisular por las quemaduras produce un aumento de la actividad de las fibras C (fibras delgadas, amielínicas y de conducción lenta) y una disminución de la conducción de las fibras A delta (fibras gruesas, mielínicas, de conducción rápida). Las fibras $\mathrm{C}$, cuyos receptores son las terminaciones libres con actividad polimodal (activadas por estímulos de presión, tacto y temperatura), al sufrir una quemadura, se transforman en nociceptores con actividad unimodal, es decir, que cualquier tipo de estímulo es percibido sólo como dolor.

\section{Alteración de la modulación}

Se sabe que dos lesiones térmicas idénticas producirán un dolor que variará mucho de un paciente a otro y en un mismo paciente a lo largo de su evolución. También es sabido que la sensación dolorosa está influida por diversas variables sicológicas que pueden hacer variar la percepción del dolor. Esto, por lo tanto, implica la existencia de circuitos que modulan la actividad de las vías transmisoras del dolor. Este mecanismo, conocido como modulación del dolor ${ }^{10,15,16,18}$, puede ser excitatorio o inhibitorio. Las quemaduras aumentan la modulación excitatoria, con producción de sensibilización periférica y sensibilización central; además, disminuyen la modulación inhibitoria, resultando con todo lo anterior en un aumento de la sensibilidad dolorosa:

\section{Sensibilización periférica}

La injuria térmica de los tejidos produce la liberación de mediadores inflamatorios $\left(\mathrm{K}^{+}, \mathrm{H}^{+}\right.$, bradikininas, histamina, 5 hidroxitriptamina, ATP y óxido nítrico) y la activación de la vía del ácido araquidónico, con la producción de prostaglandinas y leucotrienos. Algunos de estos mediadores activan los nociceptores directamente y producen dolor espontáneo.

Los mediadores inflamatorios actúan modificando la respuesta de la primera neurona y con ello al estímulo, produciendo una reducción en el umbral al dolor de los nociceptores.

\section{Sensibilización central ${ }^{13,18,19}$}

En el asta dorsal de la médula espinal, los estímulos repetitivos e intensos activan los receptores postsinápticos conocidos como n-metil d-aspartato (NMDA). La activación de estos receptores produce aumentos de la excitabilidad neuronal.

También los grandes estímulos dolorosos están asociados con la liberación de otros neuropéptidos, incluyendo la sustancia $\mathrm{P}$, que por la vía de los receptores de neurokinina tipo 1 (NK-1), generan un aumento en la duración de los potenciales lentos de las fibras A delta y fibras $C$ en el asta dorsal de la médula espinal, permitiendo con esto la sumación durante la descarga de los nociceptores y generando un aumento en la despolarización del asta dorsal. Por tanto, unos pocos segundos de estímulo de las fibras $\mathrm{C}$, producen varios minutos de despolarización postsináptica.

La despolarización acumulativa producirá la activación de los receptores NMDA y posiblemente de los receptores NK-1. Esto ocurre de la siguiente secuencia:

- Los receptores NMDA se encuentran en las neuronas potsinápticas del asta dorsal de la médula espinal normalmente inactivos. 
- Primero los estímulos dolorosos no intensos producirán liberación de glutamato de las fibras $\mathrm{C}$ y A delta, sin activar los receptores NMDA.

- Si el estímulo doloroso es más intenso, se produce liberación de glicina, que debe actuar sobre el receptor NMDA como un coagonista excitatorio al remover el $\mathrm{Mg}^{++}$, que estabiliza al NMDA ( $\sin$ lo cual no puede manifestarse el receptor NMDA).

- El $\mathrm{Mg}^{++}$en el canal del receptor NMDA, es removido por la despolarización acumulativa.

- Son activados los receptores postsinápticos NMDA.

- El aumento de la actividad de los receptores NMDA, hace que un mayor flujo de calcio ingrese al interior de la neurona postsináptica, aumentando la fosforilación neuronal y ocasionando una mayor apertura de los receptores NMDA.

- En respuesta a cada estímulo recibido desde la neurona precedente, se amplifica la intensidad y la frecuencia de las espigas transmitidas hacia el cerebro.

- Una vez procesada la información nociceptiva, esta accede a centros superiores, donde se ponen en marcha las respuestas vegetativas, motoras y emocionales y así el dolor se hace conciente.

La alteración de la sensibilización tanto periférica como central producirá los fenómenos patológicos de hiperalgesia térmica, alodinia térmica e hiperexcitabilidad térmica (Figura 2).

\section{Hiperalgesia térmica $a^{15-18}$}

Es la amplificación nociceptiva que hace que las quemaduras sean intensamente dolorosas.

Se debe al sistema modulador excitatorio del dolor, existente en todas las sinapsis de la vía nociceptiva, fundamentalmente en aquellas neuronas que emplean canales de calcio para regular su umbral de respuesta y generar un impulso propagado. Puede ser primaria o secundaria:

- La hiperalgesia térmica primaria, es el fenómeno por el cual estímulos dolorosos producen aumento de la respuesta dolorosa en la zona de la quemadura. Es una manifestación de la sensibilización periférica y central. La hiperalgesia térmica primaria es mediada por la sensibilización de los mecanorreceptores térmicos de las fibras $\mathrm{C}$ y mecanorreceptores térmicos de fibras A delta de tipo I, produciendo una sensibilización espinal, vía sistema de los receptores NMDA.

- La hiperalgesia térmica secundaria, se refiere al dolor que los estímulos dolorosos producen en zonas indemnes perilesionales ${ }^{17}$. Se debe a la sensibilización central ${ }^{19}$.

\section{Alodinia térmica}

Es el fenómeno por el cual un estímulo habitualmente no doloroso produce dolor, como es el caso de las corrientes de aire sobre una quemadura descubierta. Es mediada por fibras A beta (de mayor diámetro).

\section{Hiperexcitabilidad (Wind-up) ${ }^{20}$}

Los estímulos repetidos en fibras $\mathrm{C}$ aumentan el tamaño de los campos receptivos y producen un aumento de la respuesta de las neuronas nociceptivas espinales. Se ha demostrado que la respuesta sigue potenciada durante algunos minutos después de retirar el estímulo doloroso, llamado también "dolor persistente". Con esto se libera más glutamato, lo que activa más cantidad de receptores NMDA, manteniendo así la hiperalgesia y la alodinia térmica.

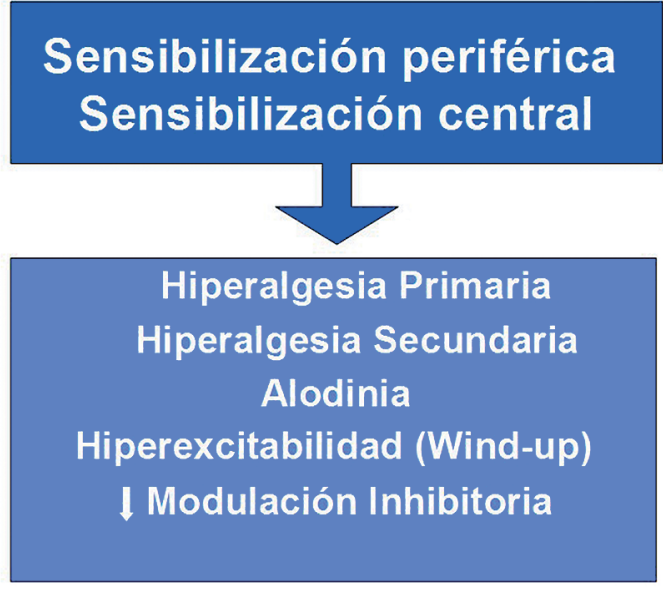

Figura 2. La alteración de la sensibilización, tanto periférica como central, produce hiperalgesia térmica, alodinia térmica e hiperexcitabilidad térmica. 


\section{Componente neuropático ${ }^{21-23}$}

Se cree que el componente neuropático estaría presente desde la etapa aguda en el paciente quemado, ya que:

- Existen similitudes de manifestaciones clínicas entre el dolor neuropático y el dolor por quemadura.

- Existe relación entre el origen fisiopatológico del dolor neuropático y el origen de la injuria en quemados, ya que las quemaduras producen daño de las terminaciones libres.

- Sorprendentemente, el tratamiento de dolor neuropático es también útil para tratar el dolor en los pacientes con quemaduras ${ }^{22}$.

El dolor por quemadura de tipo neuropático ha sido descrito en:

- La regeneración de las terminaciones libres quemadas.

- La deficiencia en la reinervación de las cicatrices.

- Las amputaciones debidas principalmente a quemaduras eléctricas.

Se sabe que los pacientes luego del alta pueden seguir sintiendo dolor o parestesias, que pueden persistir por años ${ }^{24-26}$.

La literatura reporta una incidencia de dolor neuropático en alrededor del $40 \%$ de los pacientes quemados y de fenómenos parestésicos en alrededor del 70\%. La incidencia es proporcional a la gravedad de las quemaduras y produce una alteración de la actividad diaria en un 55\% de los pacientes $^{22,25}$.

\section{Trastorno sicológico}

El trauma térmico produce una importante repercusión en la esfera sicológica del paciente, debido al intenso sufrimiento físico, personal, familiar y social. Además, las cicatrices producidas por quemadura, más allá de ser una grave secuela per se, tienen una repercusión que va más allá de las molestias y limitaciones físicas, pudiendo llegar a tener importantes consecuencias psicológicas, capaces de limitar las relaciones personales y sociales de sus afectados.

Los pacientes que sufren quemaduras tienen un grado elevado de ansiedad y una permanente atención en los estímulos generadores de dolor, lo que origina un mayor grado de percepción dolorosa y, por esto, los mecanismos endógenos inhibitorios están disminuidos.

\section{Clasificación del dolor en quemados}

El dolor en quemados se clasifica según el grado de quemaduras, el tipo de dolor y la etapa de evolución:

\section{Según grado de quemadura}

- Primer grado: quemadura de profundidad superficial; daño de la epidermis, dolor moderado. Responde bien a los analgésicos no opioides y a los opioides débiles.

- Segundo grado: quemadura de profundidad intermedia; involucra epidermis y cantidad variable de dermis con sus terminaciones libres. Son las más dolorosas, sobre todo las de segundo grado superficial. Las quemaduras críticas responden sólo a opioides potentes y las menos intensas a los opioides débiles.

- Tercer grado: llamadas también quemaduras profundas; involucra la destrucción completa de los nociceptores cutáneos, lo que se traduce clínicamente en ser las menos dolorosas.

\section{Según tipo de dolor}

- Dolor de reposo: dolor continuo, de moderada intensidad que se presenta durante el reposo.

- Dolor por procedimientos: aparece durante las curaciones, los cambios de apósitos, cambios de posición, cambios de ropa de cama, la terapia física, etc.

- Dolor postoperatorio: el más intenso, cede sólo a la administración de opioides potentes endovenosos.

- Dolor crónico: se mantiene después de la cicatrización de las quemaduras.

\section{Según etapas de evolución}

Las quemaduras tienen tres etapas claras de evolución y el dolor es diferente según la etapa a que nos refiramos (Figura 3 ).

- Etapa de reanimación: corresponde a las primeras $72 \mathrm{~h}$ de evolución. En esta etapa el dolor es intenso. En la mayor parte de los casos se usan opioides potentes intravenosos y en un menor porcentaje, opioides débiles.

- Etapa aguda: corresponde al período entre las $72 \mathrm{~h}$ y el cierre de las heridas ( 3 a 5 semanas). El dolor es oscilante en el tiempo, durante las horas del día y durante los días, con un nivel basal mantenido que corresponde al 


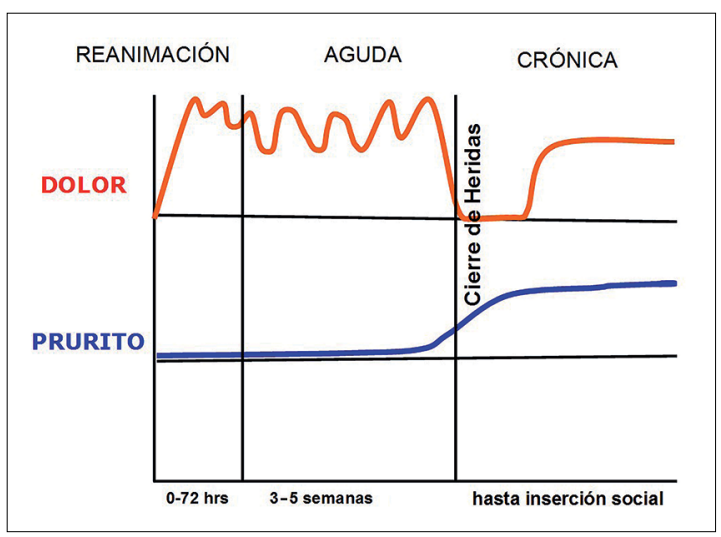

Figura 3. Etapas de evolución del dolor en quemados.

dolor de reposo y elevaciones que corresponden a los procedimientos de sala y quirúrgicos. En suma, el dolor es inicialmente muy intenso y va declinando en la medida que se van recuperando las quemaduras.

- Etapa crónica: corresponde al período que va desde el cierre de las heridas hasta la reinserción. Puede prolongarse durante varios meses. Gran parte del manejo del dolor es ambulatorio, en el contexto de la rehabilitación, por lo que sigue siendo importante un manejo adecuado del dolor, debiendo recurrirse a fármacos en presentaciones orales. De no existir contraindicación, en esta etapa se recurre de forma más liberal al uso de AINEs.

\section{Evaluación de dolor}

Bayat et al., en su artículo de sedoanalgesia sobre dolor asociado a procedimientos sugiere que se alcanzan mejores resultados si existen 3 pilares en el manejo ${ }^{28}$ :

1. Conocer los mecanismos del dolor en el paciente quemado y los cambios fisiopatológicos en sus distintas etapas de evolución.

2. Medir adecuadamente el dolor: evaluación del dolor.

3. Administrar las terapias adecuadas, tanto quirúrgicas, como farmacológicas y no farmacológicas: tratamiento del dolor.

Habiendo revisado los mecanismos que explican las particularidades del dolor en los pacientes quemados, restan 2 puntos por exponer de acuerdo a lo sugerido por Bayat: evaluación y tratamiento del dolor.

Es muy importante evaluar constantemente el dolor para guiar el manejo y, al mismo tiempo, evaluar su respuesta. Se debe considerar:

- Anamnesis del dolor: localización, carácter, intensidad, temporalidad, factores agravantes $\mathrm{y}$ atenuantes.

- Examen físico acotado: permite detectar vendajes compresivos, extremidades edematosas que requieran elevación, infecciones, presencia de tejido necrótico por un síndrome compartamental, etc.

- Aplicación de una escala adecuada: el dolor es de difícil estandarización, por eso han surgido distintas herramientas clínicas para pesquisarlo y estratificarlo ${ }^{29,30}$.

Una escala ideal debería ser sensible, precisa, confiable, reproducible y validada ${ }^{29}$. Estas escalas deberían ser aplicadas luego de asegurarse que el paciente las comprende. Como mínimo deben ser aplicadas en forma horaria en el paciente con dolor; si no es así, por lo menos dos veces al día ${ }^{39}$. Puesto que considerar el dolor como quinto signo vital es muy importante en el manejo del dolor, la implementación de una escala se hace indispensable.

Existe un sinnúmero de escalas que han sido utilizadas en la estimación de la intensidad del dolor, de las cuales, las más utilizadas se comentan brevemente a continuación ${ }^{33}$.

\section{Escala visual análoga (EVA)}

Consiste en una línea horizontal de 10 centímetros de largo, donde el cero representa la ausencia de dolor y 10 el peor dolor posible; en ella, el clínico documenta en centímetros el punto seleccionado por el enfermo. Ha sido modificada con distintos tamaños y se le ha agregado imágenes para una mejor comprensión por parte del paciente (Figura 4). Es una herramienta válida, fácilmente comprensible, que se correlaciona bien con la escala numérica análoga. Los resultados de las mediciones deben considerarse con un error de \pm 2 . Sin embargo, no está libre de desventajas, como la necesidad de que el paciente tenga buena coordinación motora y visual, siendo que está limitada en los pacientes ancianos, en aquellos con alteraciones de la vista y en los pacientes sedados. Un valor inferior a 4 en 


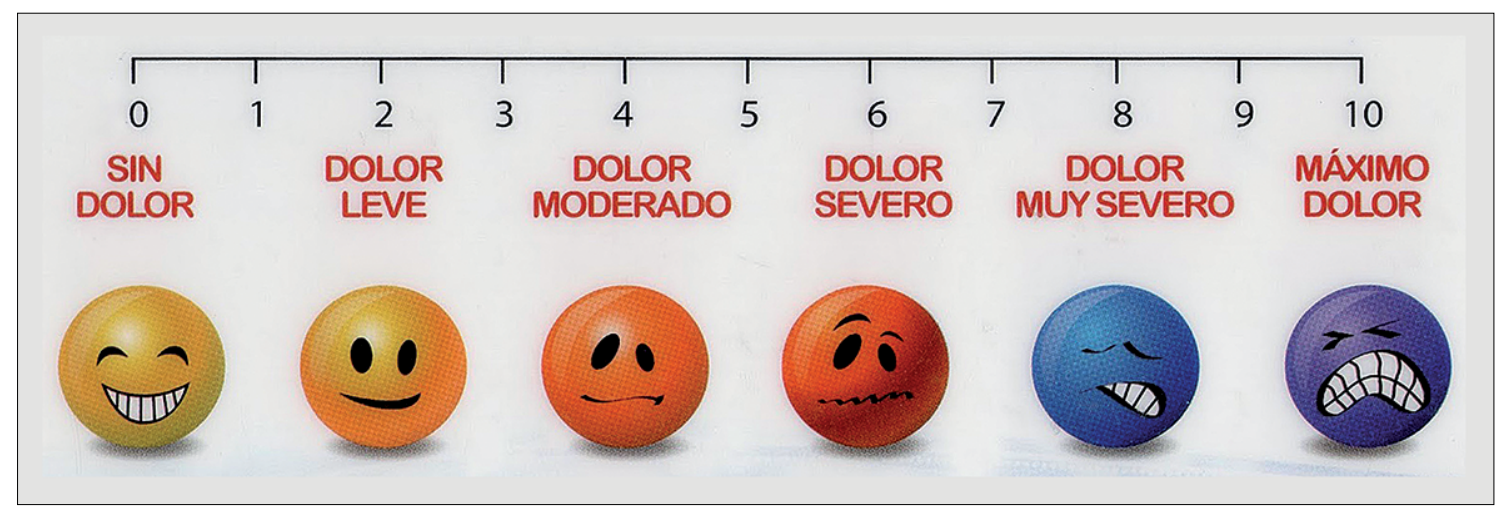

Figura 4. Ejemplo de escala visual análoga modificada, de modo que a los números se agrega la imagen de una cara que ayuda al paciente a manifestar la intensidad del dolor. Debe ser considerada como el quinto signo vital.

la EVA significa dolor leve o leve-moderado; un valor entre 4 y 6 implica la presencia de dolor moderado-grave, y un valor superior a 6 manifiesta la presencia de un dolor muy intenso ${ }^{33}$.

\section{Escala numérica análoga (ENA)}

Es una escala verbal en la cual se le solicita al enfermo que caracterice su dolor en escala del 0 al 10; el valor de cero corresponde a la ausencia de dolor y el 10 el peor dolor posible. Puede ser hablada o escrita, lo que la hace más útil en pacientes críticos o geriátricos ${ }^{34}$.

La EVA y la ENA, previamente descritas, son las escalas de dolor más usadas en los estudios realizados en pacientes quemados. Ambas son confiables y están validadas en este grupo, y ninguna ha demostrado ser superior a la otra en término de resultados ${ }^{29}$. De hecho, ambas son usadas indistintamente en el Centro de derivación de manejo del gran quemado del Hospital de Urgencias Asistencia Pública (HUAP).

\section{Escala descriptiva verbal}

Requiere de un grado de comprensión menos elevado que la EVA o ENA. Consta de sólo 4 puntos, en que el dolor puede estar ausente $=1$, ligero $=2$, moderado $=3$ o intenso $=4$. La correspondencia de la escala descriptiva con la numérica sería: dolor ausente $=0$, leve $=1-3$, moderado $=4-6$ e intenso $=7-10$. Puntuaciones $>3$ por la escala numérica o 3 por la escala verbal son inaceptables y deben aplicarse medidas analgésicas ${ }^{35}$.

\section{Termómetro de lowa}

Imagen en forma de termómetro dispuesto en forma vertical, que posee una graduación de trasparencia hasta el rojo intenso, indicando el máximo dolor. Al costado presenta referencias escritas sobre intensidad del dolor ${ }^{36}$. Ha demostrado ser de mucha utilidad en pacientes adultos mayores con déficit cognitivo moderado a severo o que tienen dificultades en comunicarse verbalmente (Figura 5).

La presencia de dolor provoca un estímulo simpático asociado a cambios fisiológicos como hipertensión arterial, taquicardia, sudoración, midriasis o lagrimeo. Sin embargo, estos signos no son específicos, especialmente en un paciente crítico, ya que pueden ser causados por vasopresores, bloqueadores beta adrenérgicos, antiarrítmicos, sedantes, condiciones patológicas (sepsis, shock, hipoxemia) y estrés. De este modo, el control de estos síntomas con analgésicos puede ser clave como indicador de presencia del dolor ${ }^{37}$.

Se recomienda evaluar el dolor en pacientes con dificultades en la comunicación mediante la utilización de escalas relacionadas con el comportamiento e indicadores fisiológicos y considerar los cambios en estos parámetros luego de la administración de analgésicos ${ }^{35}$.

\section{Escala conductual Behavioral Pain Scale (BPS)}

Surge como resultado de esta recomendación y constituye la primera escala conductual creada para pacientes sedados en las UCI. El instrumen- 


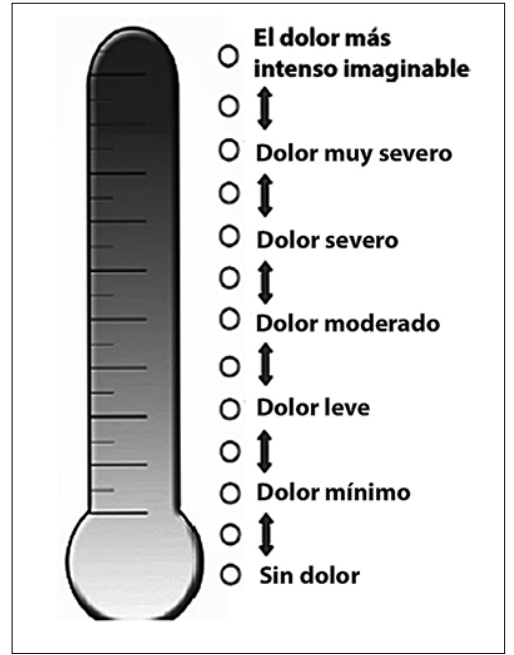

Figura 5. Termómetro de Iowa para la evaluación del dolor.

to valora con un puntaje de 1-4 la expresión facial, la movilidad y conducta de las extremidades superiores y la presencia o no de lucha contra el ventilador. La puntuación va de un mínimo de 3 (relajado y tolerando movimientos), hasta un máximo de 12 . Si la puntuación es $\geq 6$ se considera que el dolor es inaceptable. Su principal limitación es que mide presencia de dolor, pero no su intensidad ${ }^{38}$. Es considerada confiable y está validada en pacientes críticos médicos, quirúrgicos y de trauma, pero no específicamente en los pacientes quemados. Posteriormente, han surgido modificaciones a esta escala, pero que aún no cuentan con una evidencia adecuada (Tabla 1).
Tabla 1. Elementos de la escala conductual Behavioral Pain Scale (BPS)

\begin{tabular}{|lc|}
\hline Escala BPS & Puntaje \\
Expresión facial & \\
$\quad$ Relajada & 1 \\
$\quad$ Parcialmeate tensa & 2 \\
$\quad$ Totalmente tensa & 3 \\
$\quad$ Haciendo muecas & 4 \\
Movimientos de los miembros superiores & \\
$\quad$ Relajado & 1 \\
$\quad$ Parcialmente flexionados & 2 \\
$\quad$ Totalmente flexionados & 3 \\
$\quad$ Totalmente contraído & 4 \\
Ventilación mecánica & \\
$\quad$ Tolerando movimientos & \\
$\quad$ Tosiendo, pero tolerando durante la mayor & 1 \\
parte del tiempo & 2 \\
$\quad$ Luchando contra el ventilador & \\
Imposibilidad de controlar el ventilador & 4 \\
\hline
\end{tabular}

\section{Escala de dolor Abbey}

Validada en pacientes con alteraciones cognitivas, y en aquellos pacientes incapaces de usar otras escalas ${ }^{39}$. La escala de Abbey aporta un método fiable, válido y fácil de aplicar en la cabecera del enfermo para la detección del dolor en pacientes que no pueden comunicarse. Evalúa 6 parámetros: vocalización, expresión facial, cambios del lenguaje corporal, cambios en el comportamiento, cambios fisiológicos y cambios físicos. Dando un puntaje a cada item el dolor se clasifica en: sin dolor (0-2 puntos), dolor leve (3-7 puntos), dolor moderado (8-13 puntos) y dolor severo ( $>$ de 14 puntos) (Tabla 2 ).

Tabla 2. Sistema de puntaje en la escala de dolor Abbey ${ }^{74}$

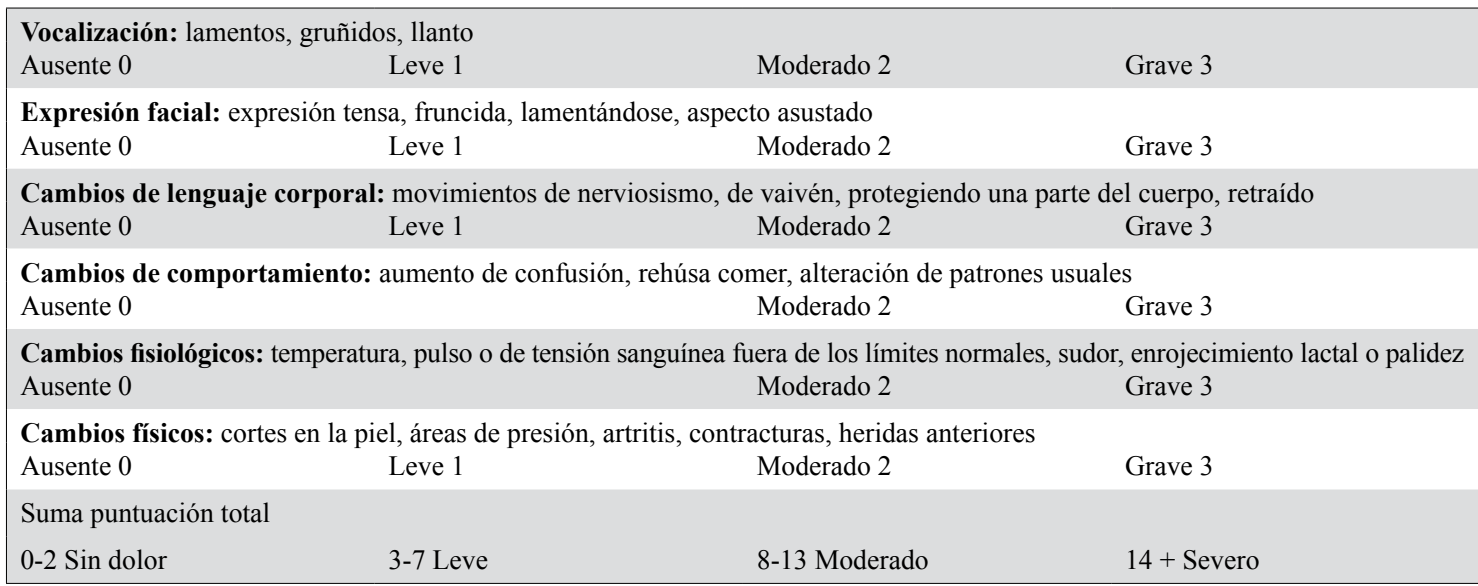


Tabla 3. Sistema de puntuación de la escala de FLACC, para niños de 1 a 3 años de edad

\begin{tabular}{|c|c|c|c|}
\hline & $\mathbf{0}$ & 1 & 2 \\
\hline Cara & No tiene expresión ni sonríe & $\begin{array}{l}\text { Ocasionalmente hace muecas o } \\
\text { frunce el ceño pero está retraído y } \\
\text { desinteresado }\end{array}$ & $\begin{array}{l}\text { Frunce el ceño con frecuencia, } \\
\text { aprieta los dientes constante o } \\
\text { frecuentemente, le tiembla el mentón }\end{array}$ \\
\hline Piernas & Posición normal o relajada & Molesto, inquieto, tenso & Patea o levanta las piernas \\
\hline Actividad & $\begin{array}{l}\text { Acostado en silencio, posición } \\
\text { normal y se mueve con facilidad }\end{array}$ & $\begin{array}{l}\text { Se retuerce, da muchas vueltas, } \\
\text { tenso }\end{array}$ & Se arquea, se pone rígido o se sacude \\
\hline Llanto & No llora (despierto o dormido) & Gime y se queja de vez en cuando & $\begin{array}{l}\text { Llora sin parar, grita o solloza y se } \\
\text { queja constantemente }\end{array}$ \\
\hline Consuelo & Tranquilo, relajado & $\begin{array}{l}\text { Se tranquiliza cuando le tocan, abra- } \\
\text { zan o le hablan, se lo puede distraer }\end{array}$ & Es difícil consolarlo o tranquilizarlo \\
\hline
\end{tabular}

\section{Escala de FLACC}

Validada en niños, especialmente de 0 a 3 años $^{39}$. La sigla FLACC, deriva de las iniciales en inglés de las variables: cara, piernas, actividad y consuelo. Es una escala para evaluar el dolor que se utiliza en pacientes no verbales, preverbales o que no pueden expresar el nivel de dolor. Se le pone un número a cada una de cinco categorías, de acuerdo a cómo ve al niño, se suma y se registra un resultado del 0 al 10 (Tabla 3).

\section{Tratamiento del dolor}

\section{Tratamiento quirúrgico}

La escara es análoga a una herida cruenta, desprovista de casi todas las funciones de la piel sana, especialmente de la función de barrera, de modo que más que proteger de las infecciones, se torna en un caldo de cultivo para la proliferación de gérmenes ${ }^{75}$. Las escaras deben ser resecadas e injertadas, o cubiertas temporalmente con heteroinjertos o coberturas sintéticas, lo antes posible. El mayor alivio del dolor se produce con el cierre de las zonas cruentas, pues altera la profundidad del tejido dañado y disminuye la carga de mediadores inflamatorios que se producen en la zona ${ }^{32,39}$.

\section{Tratamiento farmacológico}

En el paciente quemado, en fase aguda, se producen cambios en la unión de fármacos a proteínas y volúmenes de distribución, producto del manejo del shock y su estado hiperdinámico, lo que lleva a la necesidad de titular las drogas anal- gésicas, debido a la dificultad en predecir la dosis adecuada ${ }^{39}$.

En relación a la acumulación sistémica de las drogas, hay que tener en cuenta que la presencia de hipotensión arterial, trauma, sepsis, shock e hipoxemia, asociados al uso de algunos medicamentos, disminuye el flujo sanguíneo hepático y la depuración de los fármacos ${ }^{40}$.

Girtler, ha propuesto el concepto de "escalera del manejo del dolor", en que el tratamiento se divide en 3 etapas que van escalando de acuerdo a la intensidad del dolor (Figura 6). La etapa I considera el manejo de pacientes con dolor leve, con drogas no opioides, siendo escaso el número de pacientes quemados que se puede manejar a este nivel; en la gran mayoría se comienza el manejo del dolor en la etapa II. Un mismo paciente puede requerir manejo de etapa II en un momento de su evolución (en reposo por ejemplo) y escalar a etapa III durante una curación o en el postoperatorio. A estas etapas se adicionan al manejo con coadyuvantes, el uso de anestesia regional en un número limitado de casos, y el uso de terapias no farmacológicas. A este conjunto de estrategias se le denomina manejo multimodal del dolor.

A continuación se describirá las diversas alternativas de fármacos en las distintas etapas de la escalera del dolor, partiendo por los opioides y terminando con los analgésicos más débiles y coadyuvantes.

\section{Opioides}

Son analgésicos potentes, considerados la piedra angular del manejo farmacológico de los pacientes quemados; actúan uniéndose principal- 


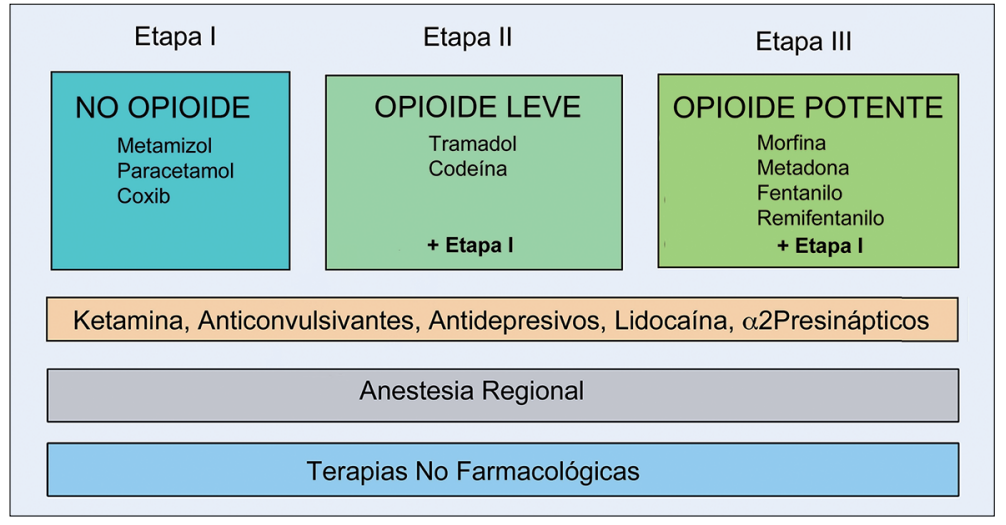

Figura 6. Escalera de manejo del dolor de los pacientes quemados. Traducido y adaptado con permiso de: Girtler R, Gustorff B. [Pain management of burn injuries]. Anaesthesist 2011; 603:243-50. mente a los receptores $\mu$ en el sistema nervioso central. Con esto logran: inhibir la liberación de neurotransmisores excitatorios (sustancia P) a nivel del ganglio de la raíz dorsal de la médula (dificultando la transmisión del estímulo doloroso), activar las vías descendentes inhibitorias (ayudando a la modulación del dolor) y modificar la actividad del sistema límbico (modificando la percepción del dolor $)^{36}$.

No hay evidencia de riesgo de desarrollar adicción mayor que la población normal (1:3.000) aunque es importante educar al paciente y su familia en este sentido ${ }^{32,39}$. Son muy buenos analgésicos pero no previenen la sensibilización central; al ser agonistas de receptores $\mu$ se relacionan con la hiperalgesia por opioides (particularmente los de acción corta administrados en infusión), por ello, su uso debería estar siempre enmarcado en un esquema de manejo multimo$\mathrm{dal}^{32}$. La activación de los receptores de NMDA/ glutamato juega un rol importante en el desarrollo de este fenómeno, por lo cual la gabapentina y la ketamina han demostrado tener un rol en su control $^{48}$. También se ha observado que el uso de coadyuvantes (AINEs, gabapentina, clonidina, dexmedetomidina, etc.) que disminuyan los requerimientos de opiodes, ayuda en el manejo de la hiperalgesia inducida por opiodes ${ }^{39,40}$.

La relación entre hiperalgesia y tolerancia no está del todo clara, pero se cree que el estado de hiperalgesia podría ser responsable de la tolerancia. Es importante buscar el desarrollo de tolerancia en pacientes con uso crónico de opiodes ( $>2$ semanas), en cuyo caso se podrá observar requerimientos de dosis mucho mayo- res de opioides a las clásicamente descritas ${ }^{32,39}$. En el caso de producirse este fenómeno, una estrategia de manejo es el cambio por otro opiode, en especial metadona por su acción antagonista NMDA $^{39,40}$.

Adicionalmente a los efectos adversos clásicamente descritos, en el contexto del manejo de este grupo existe aprehensión frente a la eventual inducción de inmunosupresión por parte de los opiodes, demostrada en estudios preclínicos, pero sin evidencia concluyente en la clínica ${ }^{49}$.

Los opiodes existen en una gran variedad de presentaciones y con una gran gama de potencia. A continuación se describirán algunos opiodes de uso frecuente en el tratamiento del dolor en los pacientes quemados:

\section{Morfina}

Es el gold standar; sus grandes ventajas son su potencia analgésica y su bajo costo. Es poco soluble en lípidos, tiene un inicio de acción relativamente lento por vía endovenosa (5 a $10 \mathrm{~min}$ ) y permite la dosificación en forma intermitente $^{42}$. Se ha utilizado en bolos endovenosos para manejar el dolor asociado a procedimientos, y en sus formulaciones de liberación prolongada o jarabe para manejo del dolor basal (requiere aumentar 2-3 veces la dosis requeridas por vía endovenosa). Durante la fase de resucitación es mejor utilizar la vía endovenosa pues puede haber enlentecimiento del vaciamiento gástrico ${ }^{32,39}$. Se desaconseja la administración subcutánea e intramuscular en el control del dolor agudo debido a su errática biodisponibilidad ${ }^{39}$. Produce un metabolito activo (morfina-6 glucorónido) que 
conforma una cinética imprevisible en la insuficiencia hepática (se reduce el metabolismo de la morfina) y en la insuficiencia renal (se reduce la depuración del metabolito), requiriéndose un ajuste de dosis o el cambio de opiode. En el shock, la eliminación es más lenta, por lo que de igual forma va a requerir ajuste de dosis ${ }^{39,43}$. No sólo reduce el dolor agudo sino que tiene impacto en el largo plazo, al disminuir el síndrome de estrés post traumático ${ }^{41}$.

\section{Fentanilo}

Es el agente analgésico de elección para pacientes ventilados, con inestabilidad hemodinámica o para pacientes que manifiesten síntomas de liberación histamínica o alergia con el uso de morfina. Tiene un rápido inicio de acción por vía endovenosa ( $1 \mathrm{~min}$ ) y una vida media relativamente corta (de 30 a 60 min) debido a una rápida distribución, por lo que es ideal para el manejo de dolor asociado a procedimiento, ya sea en infusión de corto plazo, bolos o PCA endovenosa $^{53}$. Sin embargo, su administración prolongada lleva a acumulación en los compartimentos periféricos y a un aumento de su vida media contextual (hasta 9 a $16 \mathrm{~h}$ debido a que es altamente liposoluble) y al desarrollo de tolerancia ${ }^{39,44,45}$. Se describen vías de administración alternativas: trasmucosa (para el dolor basal) e intranasal (para el dolor asociado a procedimientos, pues alcanza niveles terapéuticos en $2 \mathrm{~min})^{46}$ y transdérmica (que proporciona $72 \mathrm{~h}$ de niveles plasmáticos estables de la droga) ${ }^{32}$.

\section{Remifentanilo}

Es un opioide sintético que, debido a su metabolismo por esterasas plasmáticas, prácticamente no se acumula, pues su vida media es de sólo 3,5 $\min ^{39}$. Tampoco lo hace en pacientes con insuficiencia renal o hepática. Debe usarse en forma de infusión. Su inicio de acción es rápido (1-3 min). Dependiendo de la dosis produce efectos depresores centrales (particularmente en el paciente en el que se usa opioides por primera vez) como otros derivados de la morfina, por lo que debe usarse en pabellón o en UCI, con control de la vía aérea, si bien ha sido usado con éxito en pacientes no ventilados ${ }^{44,45}$. Es una buena alternativa para el dolor asociado a procedimientos, en la medida que no se descuide el manejo del dolor basal luego de su suspensión ${ }^{46}$. Su gran desventaja es la asociación a rápido desarrollo de tolerancia. En un estudio realizado en pacientes sometidos a cirugía abdominal, el uso de remifentanilo se asoció a mayor EVA y a mayores requerimientos de opiodes de rescate analgésico en el postoperatorio ${ }^{54}$. También ha sido usado como coadyuvante para analgesia durante procedimientos administrado en forma intranasal en dosis de 5-10 $\mu \mathrm{g} \cdot \mathrm{kg}^{-1}$, sin alterar los tiempos de recuperación ${ }^{31}$.

\section{Metadona}

Es un opioide sintético, con similares propiedades farmacológicas a la morfina, pero con vida media más larga, lo que la sitúa como buena alternativa en el manejo del dolor basal. Actúa en receptores $\mu$, pero es además un antagonista débil de los receptores NMDA, lo que le daría características especiales en la modulación de vías del dolor y en la hiperalgesia por opioides, contribuyendo a evitar la hiperalgesia secundaria, sensibilización central y dolor neuropático, todos muy frecuentes en los pacientes quemados ${ }^{32,40,50}$. $\mathrm{Su}$ administración intraoperatoria no ha mostrado mayor depresión respiratoria que la morfina. Tiene buena absorción oral pero con gran variabilidad de inicio de acción y duración ${ }^{47}$. La primera dosis debe administrarse con cautela, debido a lo impredecible de sus efectos sedantes y disfóricos ${ }^{32}$. Un pequeño estudio retrospectivo que exploró la administración temprana de metadona a grandes quemados en ventilación mecánica, concluyó que esta estrategia aumentó significativamente los días libres de ventilación mecánica en aquellos que recibieron metadona (a pesar de tener mayor superficie corporal quemada respecto de los controles), de modo que, a pesar de las limitantes metodológicas, parece adecuado intentar estudiar esta relación con un ensayo de buena calidad y, de paso, intentar dilucidar un potencial mecanismo ${ }^{50}$. Ha sido considerada la droga del switch entre una quemadura aguda y una cróni$\mathrm{ca}^{47}$. La dosis endovenosa es similar a la de morfina. También es posible administrarla por vía subcutánea, particularmente en el contexto postoperatorio, constituyendo una alternativa de manejo del dolor severo de pacientes que no se manejarán en Unidades de Paciente Crítico (UPC). La dosis oral es administrada 2 veces por día, y cuando se usa como droga de switch se calcula en base a los requerimientos previos de morfina. 


\section{Tramadol}

Es un opioide de potencia moderada, considerado un agente adecuado para el control del dolor basal moderado. También se ha descrito un efecto beneficioso en el manejo del dolor neuropático $^{30,55}$. Existe la posibilidad de administrarlo por vía endovenosa u oral, y en este último caso hay numerosas presentaciones en combinación con paracetamol lo cual ha permitido disminuir la dosis de tramadol (y sus efectos adversos), constituyéndose en una buena alternativa de manejo en sala o en el ambulatorio.

\section{Codeina}

Es más estable que la morfina cuando es administrada por vía oral. El $10 \%$ se metaboliza a morfina y el resto a norcodeína, que es excretada por el riñón. Usualmente se requiere 4 veces la dosis de morfina para un efecto analgésico equipotente ${ }^{32}$.

\section{Meperidina}

Su uso es cada día menos aconsejado pues, además de tener la décima parte de la potencia de la morfina, su metabolito, la normeperidina (que se acumula en niños, ancianos y en pacientes con falla renal) se asocia a convulsiones, confusión y mioclonías. Asimismo es, de los opiodes, el que tiene mayor potencial adictivo ${ }^{32}$. Por otro lado, se ha descrito un alto porcentaje de erupciones cutáneas luego de la administración endovenosa en pacientes quemados ${ }^{31}$.

\section{Oxicodona}

Opioide equipotente con la morfina por vía endovenosa, pero con una mejor biodisponibilidad cuando se administra por vía oral (se requiere la mitad de la dosis de morfina cuando es administrada por vía oral). Además, el prurito asociado a liberación de histamina es menos frecuente que con morfina ${ }^{39}$. En Chile se dispone de comprimidos de $10 \mathrm{mg}$.

\section{Antiinflamatorios no esteroidales (AINEs)}

Son analgésicos, antiinflamatorios y antipiréticos. Inhiben reversiblemente la ciclo-oxigenasa, inhiben la producción de prostaglandinas y a veces inhiben la vía de la lipo-oxigenasa ${ }^{40}$.

Pueden reducir los requerimientos de opiáceos hasta en un $20-30 \%$, debido al efecto sinérgico descrito $^{30}$. Dado el riesgo de falla renal y de he- morragia digestiva se usan de manera restrictiva, en población seleccionada y como coadyudante.

La inhibición de la liberación y agregación plaquetaria limita su uso en pacientes que requieren cirugías frecuentes (particularmente escarectomías e injertos, pues existe el riesgo de aumentar el sangrado postoperatorio), que resulta ser el caso de la mayoría de los grandes quemados ${ }^{30,53}$. Se pensó que había cierta expectativa con los inhibidores selectivos de la ciclo-oxigenasa 2 (al reducir la incidencia de úlceras gastrointestinales y no tener un efecto inhibitorio en la función plaquetaria), pero debido a que se evidenció incremento de riesgo trombótico cardiovascular se deben usar en grupos de pacientes selecciona$\operatorname{dos}^{30,44,45,48}$.

\section{Paracetamol (acetaminofeno)}

Su mecanismo de acción no está del todo claro. Se cree que actúa a través de la inhibición de la síntesis de prostaglandinas a nivel del sistema nervioso central ${ }^{44,45}$, de la activación de vías serotoninérgicas descendentes y de la inhibición de la actividad de la ciclo-oxigenasa $2^{40}$.

El paracetamol se ha usado para el tratamiento de dolor leve a moderado en combinación con un opioide débil y, debido al sinergismo, produce un efecto analgésico comparable al de un opioide potente ${ }^{39}$.

Tiene un muy buen perfil de seguridad, por lo que todo paciente quemado, sin contraindicación, debería tenerlo indicado para manejo del dolor basal, como una estrategia de prevención de la hiperalgesia inducida por opiodes. La dosis es de $90 \mathrm{mg} \cdot \mathrm{kg}^{-1}$ día dividido en 3-6 dosis ${ }^{39,40}$.

\section{Metamizol (dipirona)}

Pertenece a la familia de las pirazolonas. Tiene efectos analgésico (más que antiinflamatorio), antipirético y espasmolítico, al inhibir la prostaglandina sintetasa. También a nivel periférico, se ha descrito que activa la vía óxido nítrico-GMP cíclico-canales de potasio (mecanismo regulador de hiperalgesia). Centralmente activa las vías inhibitorias a nivel de la sustancia gris periacueductal ${ }^{76,77}$. Se cree que no inhiben la ciclooxigenasa (o que inhibe escasa y selectivamente la $\mathrm{COX} 3$ ), con lo cual no produciría los efectos adversos típicos de los AINEs sobre la mucosa gástrica y sobre las plaquetas. Se ha descrito como efecto adverso la agranulocitosis, 
condición potencialmente mortal, pero reversible ante un diagnóstico precoz ${ }^{30}$. La agranulocitosis es de baja incidencia $(0,1 \%)$ y además, está sujeta a variabilidad geográfica, siendo su incidencia aun más baja en América Latina ${ }^{76}$. En Chile no hay reportes de agranulocitosis a pesar de su amplio uso.

Se dispone del fármaco por vía endovenosa/ intramuscular, oral y rectal. Forma parte de la primera etapa de la escala de manejo del dolor, $\mathrm{y}$ en los pacientes quemados se suele usar como coadyuvante en el manejo multimodal del dolor.

\section{Ketamina}

Antagonista competitivo de los receptores NMDA a nivel talámico y del sistema límbico. Además, tiene efectos antiinflamatorios, al disminuir la producción de TNF $\alpha$, IL6 y radicales libres y efecto antitrombogénico ${ }^{40,48}$.

Un metaanálisis demuestra que en dosis bajas $\left(0,1 \mathrm{mg} \cdot \mathrm{kg}^{-1}\right)$ disminuye en $30 \%$ los requerimientos de opiodes ${ }^{39}$. Dosis de $0,15-0,3 \mathrm{mg} \cdot \mathrm{kg}^{-1}$ en bolo, se asocian a escasos efectos adversos (principalmente sedación, náuseas y vómitos, al usarse con morfina); con infusiones a $0,15-0,3$ $\mathrm{mg} \cdot \mathrm{kg}^{-1} \cdot \mathrm{h}^{-1}$ no se describen efectos adversos ${ }^{51}$.

Es un analgésico muy efectivo, útil en el manejo de dolor neuropático, hiperalgesia inducida por opiodes e hiperalgesia secundaria. Puede usarse como analgésico único o como coadyuvante $^{40}$. Se ha reportado su uso con buenos resultados en PCA, junto con benzodiacepinas, en el control del dolor asociado a procedimientos ${ }^{52}$.

Tiene la ventaja de mantener los reflejos de la vía aérea, la presión arterial y la frecuencia cardiaca, sin embargo, se asocia a un aumento de secreciones y a alucinaciones (con dosis más bien anestésicas de $1 \mathrm{mg} \cdot \mathrm{kg}^{-1} \mathrm{o}$ más) las que pueden ser atenuadas con la administración concomitante de benzodiacepinas y/o propofol, y que suelen ser menos frecuentes en niños ${ }^{31,39}$.

Se puede administrar por vía oral, intramuscular y endovenosa. Produce dolor a la inyección, que puede ser atenuado con el uso de lidocaína $^{39,40}$.

\section{Gabapentinoides}

Actúan a nivel periférico, uniéndose a la subunidad $\alpha_{2} \delta_{1}$ del canal de calcio voltaje dependiente del asta dorsal de la médula, con lo cual aumenta la liberación de neurotransmisores in- hibitorios ${ }^{43}$, y a nivel central disminuyen indirectamente la sobreactivación del receptor NMDA y la liberación de glutamato, explicando de ese modo su capacidad de limitar la sensibilización del sistema nervioso central ${ }^{40}$.

La gabapentina y la pregabalina son anticonvulsivantes usados principamente en el manejo del dolor neuropático y del prurito ${ }^{30,56}$.

En el control del dolor agudo la evidencia es más contradictoria. Por un lado, estudios descriptivos (serie de casos, y una pequeña cohorte con controles históricos) mostraron resultados promisorios para el uso de gabapentina en términos de control de síntomas neuropáticos, de disminución del dolor y de requerimientos de opiodes de rescate $^{57,58}$. Un reciente ensayo aleatorizado $(\mathrm{n}=$ 53) no logró reproducir esos resultados ${ }^{59}$.

La pregabalina, en un ensayo aleatorizado, usada las 4 primeras semanas luego de ocurrida la quemadura $(\mathrm{n}=90)$, disminuyó varios componentes del dolor neuropático (calor, disconfort y prurito) y disminuyó el dolor asociado a procedimientos cuando fue usada como coadyuvante de otros esquemas de sedoanalgesia (probablemente debido a su acción anti-hiperalgésica y a su efecto sedante), pero no disminuyó los requerimientos de opiodes de rescate. El perfil de la pregabalina es superior al de la gabapentina, pues permite dosificación 2 veces por día (la gabapentina 3), tiene mayor potencia y presenta un inicio más precoz de la efectividad clínica (1 semana $)^{60}$.

\section{Agonistas a2 presinápticos}

Los receptores $\alpha_{2}$ presinápticos están principalmente localizados en centros relacionados con el alerta (locus ceruleus) y el dolor (sustancia gelatinosa de la médula). Su estímulo, además, potencia las vías inhibitorias descendentes. Por ello tienen propiedades sedantes, analgésicas y simpaticolíticas (antihipertensivos) ${ }^{30}$.

Producen analgesia por estimulación del sistema inhibitorio descendente central, por el reclutamiento de neuromediadores que modulan la percepción del dolor y por inhibición de liberación de sustancia $\mathrm{P}^{40}$.

También disminuyen el delirio (muy prevalente en los pacientes quemados) y son muy útiles en el manejo de la deprivación de alcohol, benzodiacepinas, opiodes y nicotina (existe un alto porcentaje de abuso de sustancias en los pa- 
cientes quemados $)^{31,40}$; todo ello con mucho menos depresión respiratoria que otros sedantes ${ }^{61}$. Uno de los efectos más atractivos de este grupo de drogas es su posible rol en el manejo de la hiperalgesia inducida por opioides ${ }^{53}$. Se dispone de 2 agonistas $\alpha_{2}$ presinápticos:

\section{Dexmedetomidina}

Es un agonista de los receptores $\alpha 2$ presinápticos del subtipo 2A (más selectiva que la clonidina), que tiene propiedades analgésicas moderadas. En pacientes quemados anestesiados o con sedoanalgesia para ventilación mecánica ha demostrado reducir los requerimientos de anestésicos, sedantes y analgésicos ${ }^{61,62}$. Es un buen coadyuvante para la ketamina en sedoanalgesia para procedimientos, pues atenúa la estimulación cardiaca inducida por la ketamina y previene el delirio. Además, ambas mantienen la ventilación espontánea ${ }^{40}$. También ha sido administrada por vía intranasal $\left(2 \mu \mathrm{g} \cdot \mathrm{kg}^{-1}\right)$ con resultados comparables al uso de midazolam $\left(0,5 \mathrm{mg} \cdot \mathrm{kg}^{-1}\right)$ como premedicación $^{31}$. Un metaanálisis del 2013 en que la dexmedetomidina fue usada en sedoanalgesia de corto plazo (perioperatoria o para curaciones), demuestra su superioridad como sedante, pero no logra significancia en el outcome dolor; sin embargo, no se debería sacar conclusiones definitivas a partir de este estudio pues, aun siendo un metaanálisis, la muestra es pequeña y muy heterogénea ${ }^{63}$.

\section{Clonidina}

Se dispone en nuestro medio sólo de comprimidos de clonidina para administración oral; en general se usa como coadyuvante, pues como analgésico único se asocia a hipotensión ${ }^{40}$. Hay reportes de su uso en pediatría por sonda enteral a dosis de $2-5 \mu \mathrm{g} \cdot \mathrm{kg}^{-1}$ en pacientes con pobre respuesta a sedoanalgesia con opiodes y benzodiacepinas $^{31}$.

\section{Lidocaína}

Actúa bloqueando los canales de sodio voltaje dependientes, con lo cual bloquea el influjo de sodio, causando inhibición de la propagación de los potenciales de acción en las neuronas. De ese modo, disminuye la transmisión en terminaciones aferentes, modula la transmisión a nivel del asta dorsal de la médula, modifica la percepción del dolor a nivel central y, además, tiene efecto antiinflamatorio ${ }^{40,64}$.

Debido a su acción multimodal es una alternativa en el manejo del dolor neuropático (principalmente cuando se asocia a daño nervioso) o tolerancia a opiodes ${ }^{30,39,53}$.

En dolor agudo, un ensayo cross-over controlado $(n=45)$ mostró que, asociada a morfina, en dolor relacionado a procedimientos, logró disminuir el dolor, pero no los niveles de ansiedad ni el requerimiento de opioides de rescate. El régimen fue de $1,5 \mathrm{mg} \cdot \mathrm{kg}^{-1}$ de lidocaína endovenosa en bolo, seguido de 2 bolos de $0,5 \mathrm{mg} \cdot \mathrm{kg}^{-1}$ separados por $5 \mathrm{~min}$, más una infusión de $2 \mathrm{mg} \cdot \mathrm{min}^{-1}$; la morfina fue administrada por PCA endovenosa ${ }^{64}$. A propósito de este estudio, una revisión Cochrane de 2014 consideró a la lidocaína endovenosa como agente farmacológico bajo investigación, y sugirió la realización de ensayos bien diseñados y conducidos a fin de determinar su efectividad en este escenario ${ }^{65}$.

En un ensayo no controlado en niños quemados $(n=14)$ con dolor neuropático localizado en zonas reepitelizadas o injertadas (pacientes sin zonas cruentas), se administró lidocaína en fracciones de parches al $5 \%$ por $12 \mathrm{~h}$ diarias como monoterapia. Después de 3 meses de observación, el dolor prácticamente desapareció en todos los pacientes y bajó a cerca de la mitad después de una semana del inicio del estudio. Además se midió concentraciones plasmáticas a las $0,12,36$ y $60 \mathrm{~h}$ de iniciado el estudio, no encontrándose valores asociados a toxicidad sistémica ${ }^{66}$.

\section{Antidepresivos}

La amitriptilina usada en dosis bajas (usualmente no más de $75 \mathrm{mg}$ ), es efectiva en el manejo del dolor neuropático ${ }^{30}$. Actúa activando las vías inhibitorias descendentes en la médula espinal. La administración nocturna permite aprovechar su efecto inductor del sueño asociado. Sin embargo, cerca de un tercio de los pacientes no logran efectos analgésicos adecuados debido a que deben suspender el fármaco antes de escalar dosis debido a sus efectos adversos, principalmente boca seca y visión borrosa ${ }^{53}$. El efecto analgésico ocurre tardíamente (semanas). No hay reporte de estudios en donde se inicie precozmente terapia antidepresiva en los pacientes quemados ${ }^{30}$. Los inhibidores selectivos de la serotonina son una alternativa en el caso de intolerancia a los antidepresivos tricíclicos ${ }^{30}$. 


\section{Heparina}

Tiene efectos antiinflamatorios que resultan de la desactivación de citoquinas proinflamatorias (TNF $\alpha)$, selectinas (CD11b) e integrinas (ICAM-1) y de la atenuación de la activación del complemento. Sus efectos angiogénicos derivan de su interacción interacción con VEGF (factor de crecimiento vascular endotelial) y FGF (factor de crecimiento de fibroblastos) ${ }^{67}$.

Un ensayo aleatorizado $(\mathrm{n}=58)$ de aplicación tópica (2.400 UI por cada $1 \%$ de superficie corporal quemada, 3 veces al día) en comparación con una terapia estándar, evidenció una mejor analgesia (tanto en términos de menores puntajes de dolor como de requerimientos de analgesia de rescate), sin aumentar los efectos adversos, salvo un leve sangrado en la zona de aplicación de la heparina ( $\sin$ diferencia en los requerimientos de hemoderivados ni de resultados de las pruebas de laboratorio: TTPK, recuento plaquetario, etc.) ${ }^{67}$. Posteriormente, se publicó una serie de casos (n $=6$ ) en donde luego de la administración tópica de heparina, el dolor severo desapareció o se tornó leve y, además, se previno cicatrices y contracturas ${ }^{68}$. Por último, un estudio de cohortes de niños con 5- 45\% de superficie corporal quemada $(\mathrm{n}=100)$ mostró que el uso de heparina tópica en comparación con una terapia estándar disminuyó el dolor, los requerimientos de otros analgésicos, las curaciones, los requerimientos de antibióticos y de fluidos, los días de hospitalización, el tiempo en que sanó la quemadura, los requerimientos de injerto, los costos y la mortalidad ${ }^{69}$.

\section{Benzodiacepinas}

Son ansiolíticos usados como cooadyuvantes en el manejo del dolor (si bien no son analgésicos). La ansiedad asociada al dolor basal y a la anticipación del dolor relacionado con procedimientos, exacerba la percepción del dolor, agravando también la ansiedad, desencadenando así un círculo vicioso y dando también cabida al desarrollo de estrés postraumático ${ }^{32,40}$. Además, la mantención de un tono simpático elevado exacerba el catabolismo, con lo cual se deteriora la cicatrización $^{31}$.

Las benzodiacepinas actúan amplificando el GABA en el sistema nervioso central y disminuyendo las catecolaminas a nivel periférico. Pueden producir depresión respiratoria y tolerancia de rápida instalación ${ }^{40}$.
Debido a su rápido inicio de acción, el midazolam es una buena alternativa como coadyuvante en el manejo de la sedoanalgesia del dolor asociado a procedimientos ${ }^{30,52}$.

\section{Óxido nitroso}

Es autoadministrado como analgésico para el dolor asociado a procedimientos. El éxito en la administración depende de la habilidad del paciente de sujetar la mascarilla.

Debido a su baja potencia anestésica debe ser usado en concentraciones altas: 50-70\% (mezclado con oxígeno) a fin de lograr el efecto deseado. Es de rápido inicio (segundos). Su uso está limitado por las náuseas y vómitos. Aunque la posibilidad es escasa, existe el riesgo de toxicidad con el uso crónico, tanto del paciente como de los profesionales de la salud. Afecta el metabolismo de la vitamina $\mathrm{B}_{12}$, y con ello contribuye a la degeneración subaguda de la médula espinal; los pacientes desnutridos están expuestos a un mayor riesgo de complicaciones ${ }^{30,32,39}$.

\section{Sulfato de magnesio}

Es antagonista de los receptores NMDA. Hay 2 metaanálisis que muestran que es un efectivo coadyuvante analgésico en el perioperatorio en dosis de $30-50 \mathrm{mg} \cdot \mathrm{kg}^{-1}$, mejorando los puntajes de dolor y los requerimientos de analgesia de rescate, sin efectos adversos asociados ${ }^{70,71}$. También se evidenció una disminución de los calofríos respecto al grupo control ${ }^{71}$. No hay reportes en la literatura de su uso en pacientes quemados, pero sin duda es una alternativa atractiva de explorarse en este grupo, particularmente por su acción anti-NMDA y el rol que pudiera tener en la prevención y/o manejo de la hiperalgesia inducida por opiodes.

\section{Anestesia regional}

$\mathrm{Su}$ uso ha sido limitado en grandes quemados debido a que muchos de ellos cursan con inestabilidad hemodinámica y/o sepsis, por lo que las técnicas neuroaxiales están contraindicadas en forma relativa o absoluta. Además, respecto de las técnicas regionales, tanto las zonas quemadas como las donantes suelen abarcar más territorio del que es factible de cubrir con un solo bloqueo $^{48}$.

Privilegiando las zonas donantes, un ensayo $(n=20)$ de bloqueo continuo $(72 \mathrm{~h})$ con ropi- 
vacaína versus inyección de solución salina de la fascia ilíaca, mostró que el primer grupo tenía menos dolor y menos requerimientos de opiodes y benzodiacepinas ${ }^{72}$. Posteriormente, el mismo autor diseñó un ensayo en el que asignó 81 pacientes a 3 grupos: bloqueo de la fascia ilíaca con bolo de ropivacaína más infusión de ropivacaína (bloqueo continuo), otro a bloqueo de la fascia ilíaca con bolo de ropivacaína más infusión de solución salina (single shot), y un último grupo a bloqueo de la fascia ilíaca con bolo más infusión de solución salina (control); concluyó que los 2 primeros grupos fueron superiores al control respecto de dolor, requerimiento de opiodes y efectos adversos asociados a su uso. Además, mostró que el bloqueo continuo no muestra ventajas respecto a la inyección única, sino por el contrario, los pacientes que recibieron inyección única, tuvieron menos paresia residual y mejor satisfacción en el manejo del dolor ${ }^{73}$.

\section{Técnicas no farmacológicas}

Factores como la ansiedad, la depresión y la alteración del ciclo sueño/vigilia, pueden alterar la percepción del dolor, por lo cual es altamente recomendado un manejo multidisciplinario del dolor en los pacientes quemados. Diversas técnicas no farmacológicas han demostrado efectividad como coadyuvantes a las terapias farmacológicas habituales, dentro de las cuales destacan: técnicas de relajación, distracción, hipnosis, musicoterapia, realidad virtual (mundos generados por computador), masoterapia, condicionamiento clásico (se logra tratando agresivamente el dolor desde el comienzo del tratamiento) ${ }^{31,39,40}$. Este manejo debe ser iniciado precozmente a fin de prevenir el desarrollo de ansiedad, la que perpetúa el ciclo del dolor ${ }^{30,40,48}$.

\section{Conclusiones}

El dolor en los pacientes quemados es un fenómeno complejo, muy frecuentemente subestimado y subtratado. Es multifactorial, amplificado y modulado en diferentes sitios, tanto a nivel periférico como central y, por tanto, puede no ser completamente controlado por un solo agente. Un esquema multimodal de manejo debería prevenir o reducir la hiperalgesia asociada al uso de opiodes potentes de acción corta.

Existen 3 pilares en el manejo del dolor del paciente quemado: 1) conocer los mecanismos que causan y perpetúan el dolor en el paciente quemado y los cambios fisiopatológicos en sus distintas etapas de evolución, de modo de generar estrategias de manejo agresivas y precoces, $\mathrm{y}$ con enfoque multidisciplinario; 2) medir adecuadamente el dolor: evaluación del dolor y 3 ) administrar las terapias adecuadas, tanto quirúrgicas, como farmacológicas y no farmacológicas: tratamiento del dolor.

Cada centro en donde se manejen pacientes quemados debe generar, de acuerdo al arsenal terapéutico disponible, guías clínicas de manejo que consideren el tratamiento del dolor basal o de reposo, del dolor asociado a procedimientos $\mathrm{y}$ al postoperatorio, del dolor neuropático y con lo anterior, aspirar en el mediano a largo plazo, a disminuir la incidencia de dolor crónico. Estas guías de manejo deben considerar el uso de una escala de medición del dolor de fácil comprensión y manejo, que se aplique de forma frecuente, teniendo en cuenta la gran variabilidad interindividual que manifiestan estos pacientes. Igualmente importante es la variabilidad dentro de la evolución de un mismo paciente a lo largo de los cambios que experimentan las lesiones (cierre, infección, formación de cicatriz retráctil, reparación de daño nervioso, etc.) y a nivel sistémico (shock, sepsis, desarrollo de tolerancia, etc.). Esa aproximación, permitirá la titulación de las terapias de acuerdo a la evaluación de cada paciente en cada etapa de evolución.

Los anestesiólogos deben contribuir al manejo del dolor del paciente quemado en varios aspectos: siendo facilitadores para que el cierre definitivo o temporal de las lesiones ocurra lo antes posible; en el manejo farmacológico del dolor (postoperatorio, asociado a procedimientos); y como interconsultores en el manejo del dolor basal, particularmente cuando se observa dolor resistente al uso de opiodes. 


\section{Referencias}

1. Latarjet $\mathrm{J}$, Choinère $\mathrm{M}$. Pain in burn patients. Burns 1995 Aug;21(5):344-348.

2. Abdi S, Zhou Y. Management of pain after burn injury. Curr Opin Anaesthesiol 2002 Oct;15(5):563-567.

3. Faucher L. Modern pain Management in Burn Care. Probl Gen Surg 2003;20(1):80-87.

4. Danilla Enei S, Pastén Rojas J, Fasce Pineda G et al. Mortality trends from burn injuries in Chile: 1954-1999. Burns 2004 Jun;30(4):348-356.

5. Patterson DR, Hofland HW, Espey K et al. Nursing Committee of the International Society for Burn Injuries. Pain management. Burns 2004 Dec;30(8):A10-A15.

6. Latarjet J. [The pain from burns]. Pathol Biol (Paris) 2002 Mar;50(2):127-133.

7. Pal SK, Cortiella J, Herndon D. Adjunctive methods of pain control in burns. Burns 1997 Aug;23(5):404-412.

8. Marks RM, Sachar EJ. Undertreatment of medical inpatients with narcotic analgesics. Ann Intern Med 1973 Feb;78(2):173181.

9. Perry SW. Under medication for pain on a burns unit of narcotic usage in the treatment of pain. JAMA 1984;6:308-316.

10. Schnurrer JA, Marvin JA, Heimbach DM. Evaluation of pediatric medications in burns. Burn Care Rehabil 1985;6(2):105-107.

11. Choinière M, Melzack R, Girard $\mathrm{N}$ et al. Comparisons between patients' and nurses' assessment of pain and medication efficacy in severe burn injuries. Pain 1990 Feb;40(2):143-152.

12. Friedland LR, Pancioli AM, Duncan KM. Pediatric emergency department analgesic prac- tice. Pediatr Emerg Care 1997 Apr;13(2):103-106.

13. Singer AJ, Thode HC Jr. National analgesia prescribing patterns in emergency department patients with burns. J Burn Care Rehabil 2002 NovDec;23(6):361-365.

14. Wright C, Goudas LC, Bentch A et al. Hyperalgesia in outpatients with dermal injury: quantitative sensory testing versus a novel simple technique. Pain Med 2004 Jun;5(2):162-167.

15. Coderre TJ, Katz J, Vaccarino AL et al. Contribution of central neuroplasticity to pathological pain: review of clinical and experimental evidence. Pain 1993 Mar;52(3):259-285.

16. Besson JM. The neurobiology of pain. Lancet 1999 May;353(9164):1610-1615.

17. Carr DB, Goudas LC. Acute pain. Lancet 1999 Jun;353(9169):2051-2058.

18. Kidd BL, Urban LA. Mechanisms of inflammatory pain. Br J Anaesth 2001 Jul;87(1):3-11.

19. Nozaki-Taguchi N, Yaksh TL. Pharmacology of spinal glutamatergic receptors in postthermal injury-evoked tactile allodynia and thermal hyperalgesia. Anesthesiology 2002 Mar;96(3):617-626.

20. Nozaki-Taguchi N, Yaksh TL. Spinal and peripheral mu opioids and the development of secondary tactile allodynia after thermal injury. Anesth Analg 2002 Apr;94(4):968-974.

21. Pedersen JL, Andersen OK, Arendt-Nielsen L et al. Hyperalgesia and temporal summation of pain after heat injury in man. Pain 1998 Feb;74(2-3):189-197.

22. Woolf CJ, Mannion RJ. Neuropathic pain: aetiology, symptoms, mechanisms, and management. Lancet 1999
Jun;353(9168):1959-1964.

23. Malenfant A, Forget R, Papillon

$\mathrm{J}$ et al. Prevalence and characteristics of chronic sensory problems in burn patients. Pain 1996 Oct;67(2-3):493-500.

24. Malenfant A, Forget R, Amsel R, et al. Tactile, thermal and pain sensibility in burned patients with and without chronic pain and paresthesia problems. Pain 1998 Sep;77(3):241-251.

25. Choinière M, Melzack R, Papillon J. Pain and paresthesia in patients with healed burns: an exploratory study. J Pain Symptom Manage 1991 Oct;6(7):437444.

26. Dauber A, Osgood PF, Breslau AJ et al. Chronic persistent pain after severe burns: a survey of 358 burn survivors. Pain Med 2002 Mar;3(1):6-17.

27. Nedelec B, Hou Q, Sohbi I et al. Sensory perception and neuroanatomical structures in normal and grafted skin of burn survivors. Burns 2005 Nov;31(7):817-830.

28. Bayat A, Ramaiah R, Bhananker SM. Analgesia and sedation for children undergoing burn wound care. Expert Rev Neurother 2010 Nov;10(11):1747-1759.

29. Mahar PD, Wasiak J, O'Loughlin CJ et al. Frequency and use of pain assessment tools implemented in randomized controlled trials in the adult burns population: a systematic review. Burns 2012 Mar;38(2):147-154.

30. Alencar de Castro RJ, Leal PC et al. Pain management in burn patients. Braz J Anesthesiol 2013 Jan-Feb;63(1):149-153.

31. David N. Herndon. Total Burn Care: Expert Consult - Online and Print. Chapter 64: Management of pain and other discomforts in burned patients. Walter J. Meyer III, Shelley 
Wiechman, Lee Woodson, Mary Jaco, Christopher R. Thomas.

32. Faucher L, Furukawa K. Practice guidelines for the management of pain. J Burn Care Res 2006 Sep-Oct;27(5):659-668.

33. DeLoach LJ, Higgins MS, Caplan $\mathrm{AB}$ et al. The visual analog scale in the immediate postoperative period: intrasubject variability and correlation with a numeric scale. Anesth Analg 1998 Jan;86(1):102-106.

34. Sessler CN, Pedram S. Protocolized and target-based sedation and analgesia in the ICU. Crit Care Clin 2009 Jul;25(3):489513.

35. Ahlers SJ, van der Veen AM, van Dijk $M$ et al. The use of the Behavioral Pain Scale to assess pain in conscious sedated patients. Anesth Analg 2010 Jan;110(1):127-133.

36. Gélinas C, Herr K. Critical Care Nursing of Older Adults: Best Practices. 2010. Springer Publishing Company. New York. 3rd Edition. Chapter 18: 363:401.

37. Riker RR, Fraser GL. Altering intensive care sedation paradigms to improve patient outcomes. Anesthesiol Clin 2011 Dec;29(4):663-674.

38. Young J, Siffleet J, Nikoletti S et al. Use of a Behavioural Pain Scale to assess pain in ventilated, unconscious and/or sedated patients. Intensive Crit Care Nurs 2006 Feb;22(1):32-39.

39. Richardson P, Mustard L. The management of pain in the burns unit. Burns 2009 Nov;35(7):921936.

40. Retrouvey H, Shahrokhi S. Pain and the thermally injured patient-a review of current therapies. J Burn Care Res 2015 MarApr;36(2):315-323.

41. Wiechman Askay S, Patterson DR, Sharar SR et al. Pain ma- nagement in patients with burn injuries. Int Rev Psychiatry 2009 Dec;21(6):522-530.

42. Jacobi J, Fraser GL, Coursin DB et al. Task Force of the American College of Critical Care Medicine (ACCM) of the Society of Critical Care Medicine (SCCM), American Society of HealthSystem Pharmacists (ASHP), American College of Chest Physicians. Clinical practice guidelines for the sustained use of sedatives and analgesics in the critically ill adult. Crit Care Med 2002 Jan;30(1):119-141.

43. Ceraso DH, Rodríguez EC, Ferrer L. Ventilación Mecánica. Aspectos básicos y avanzados. Bogota: Distribuna Editorial; 2012.

44. Sakata RK. Analgesia y Sedación en Unidad de Cuidados Intensivos. Rev Bras Anestesiol 2010;60(6):360-365.

45. Valverde Careaga N, Rocha Luna JM. Manejo del dolor en el paciente bajo sedación leve-moderada y ventilación mecánica en el Servicio de Urgencias. Archivos de Medicina de Urgencia de México 2011;3:6-11.

46. Anderson TA, Fuzaylov G. Perioperative anesthesia management of the burn patient. Surg Clin North Am 2014 Aug;94(4):851-861.

47. Gourlay GK, Wilson PR, Glynn CJ. Pharmacodynamics and pharmacokinetics of methadone during the perioperative period. Anesthesiology 1982 Dec;57(6):458-467.

48. Gregoretti C, Decaroli D, Piacevoli $\mathrm{Q}$ et al. Analgo-sedation of patients with burns outside the operating room. Drugs 2008;68(17):2427-2443.

49. Rittner HL, Roewer N, Brack A. The clinical (ir)relevance of opioid-induced immune suppres- sion. Curr Opin Anaesthesiol 2010 Oct;23(5):588-592.

50. Jones GM, Porter K, Coffey R et al. Impact of early methadone initiation in critically injured burn patients: a pilot study. J Burn Care Res 2013 MayJun;34(3):342-348.

51. McGuinness SK, Wasiak J, Cleland $\mathrm{H}$ et al. A systematic review of ketamine as an analgesic agent in adult burn injuries. Pain Med 2011 Oct;12(10):15511558.

52. MacPherson RD, Woods D, Penfold J. Ketamine and midazolam delivered by patient-controlled analgesia in relieving pain associated with burns dressings. Clin J Pain 2008 Sep;24(7):568-571.

53. Holtman JR Jr, Jellish WS. Opioid-induced hyperalgesia and burn pain. J Burn Care Res 2012 Nov-Dec;33(6):692-701.

54. Guignard B, Bossard AE, Coste $\mathrm{C}$ et al. Acute opioid tolerance: intraoperative remifentanil increases postoperative pain and morphine requirement. Anesthesiology 2000 Aug;93(2):409417.

55. Hollingshead J, Dühmke RM, Cornblath DR. Tramadol for neuropathic pain. Cochrane Database Syst Rev 2006;(3):CD003726.

56. Goutos I, Dziewulski P, Richardson PM. Pruritus in burns: review article. J Burn Care Res 2009 Mar-Apr;30(2):221-228.

57. Gray P, Williams B, Cramond T. Successful use of gabapentin in acute pain management following burn injury: a case series. Pain Med 2008 Apr;9(3):371-376.

58. Cuignet O, Pirson J, Soudon O et al. Effects of gabapentin on morphine consumption and pain in severely burned patients. Burns 2007 Feb;33(1):81-86. 
59. Wibbenmeyer L, Eid A, Liao J et al. Gabapentin is ineffective as an analgesic adjunct in the immediate postburn period. J Burn Care Res 2014 MarApr;35(2):136-142.

60. Gray P, Kirby J, Smith MT et al. Pregabalin in severe burn injury pain: a double-blind, randomised placebo-controlled trial. Pain 2011 Jun;152(6):1279-1288.

61. Ravipati P, Reddy PN, Kumar C et al. Dexmedetomidine decreases the requirement of ketamine and propofol during burns debridement and dressings. Indian J Anaesth 2014 Mar;58(2):138142.

62. Shank ES, Sheridan RL, Ryan $\mathrm{CM}$ et al. Hemodynamic responses to dexmedetomidine in critically injured intubated pediatric burned patients: a preliminary study. J Burn Care Res 2013 May-Jun;34(3):311-317.

63. Asmussen S, Maybauer DM, Fraser JF et al. A meta-analysis of analgesic and sedative effects of dexmedetomidine in burn patients. Burns 2013 Jun;39(4):625-631.

64. Wasiak J, Spinks A, Costello V et al. Adjuvant use of intravenous lidocaine for procedural burn pain relief: a randomized double-blind, placebo-controlled, cross-over trial. Burns 2011 Sep;37(6):951-957.

65. Wasiak J, Mahar PD, McGuinness SK et al. Intravenous lidocaine for the treatment of background or procedural burn pain. Cochrane Database Syst Rev 2014;10(10):CD005622.

66. Orellana Silva M, Yáñez V, Hidalgo $\mathrm{G}$ et al. 5\% lidocaine medicated plaster use in children with neuropathic pain from burn sequelae. Pain Med 2013 Mar;14(3):422-429.

67. Barretto MG, Costa MG, Serra MC et al. [Comparative study of conventional and topical heparin treatments for burns analgesia]. Rev Assoc Med Bras 2010 JanFeb;56(1):51-55.

68. Agbenorku P, Fugar S, Akpaloo $\mathrm{J}$ et al. Management of severe burn injuries with topical heparin: the first evidence-based study in Ghana. Int J Burns Trauma 2013;3(1):30-36.

69. Venkatachalapathy TS. A comparative study of paediatric thermal burns treated with topical heparin and without heparin. Indian J Surg 2014 Aug;76(4):282-287.

70. Albrecht E, Kirkham KR, Liu SS et al. Peri-operative intravenous administration of magnesium sulphate and postoperative pain: a meta-analysis Anaesthesia 2013; 68: 79-90.

71. De Oliveira GS Jr, Castro-Alves LJ, Khan JH et al. Perioperative systemic magnesium to minimize postoperative pain: a meta-analysis of randomized controlled trials. Anesthesiology 2013 Jul;119(1):178-190.
72. Cuignet O, Pirson J, Boughrouph $\mathrm{J}$ et al. The efficacy of continuous fascia iliaca compartment block for pain management in burn patients undergoing skin grafting procedures. Anesth Analg 2004 Apr;98(4):10771081.

73. Cuignet $\mathrm{O}$, Mbuyamba J, Pirson J. The long-term analgesic efficacy of a single-shot fascia iliaca compartment block in burn patients undergoing skin-grafting procedures. J Burn Care Rehabil 2005 Sep-Oct;26(5):409-415.

74. Chamorro P, Puche E. Traducción al castellano y validación de la escala Abbey para la detección del dolor en pacientes no comunicativos. Rev Soc Esp Dolor 2013;20(1):3-7.

75. Rau KK, Spears RC, Petruska JC. The prickly, stressful business of burn pain. Exp Neurol 2014 Nov;261:752-756.

76. Buitrago-González TP, Calderón-Ospina CA, Vallejos-Narváez A. Dipirona ¿Beneficios subestimados o riesgos sobredimensionados? Revisión de la literatura. Rev Colomb Cienc Quím Farm 2014;43(1):173195.

77. Arcila-Herrera H, BarragánPadilla S, Borbolla-Escoboza JR et al. Consenso de un grupo de expertos mexicanos. Eficacia y seguridad del metamizol (dipirona). Gac Med Mex 2004 JanFeb;140(1):99-101. 